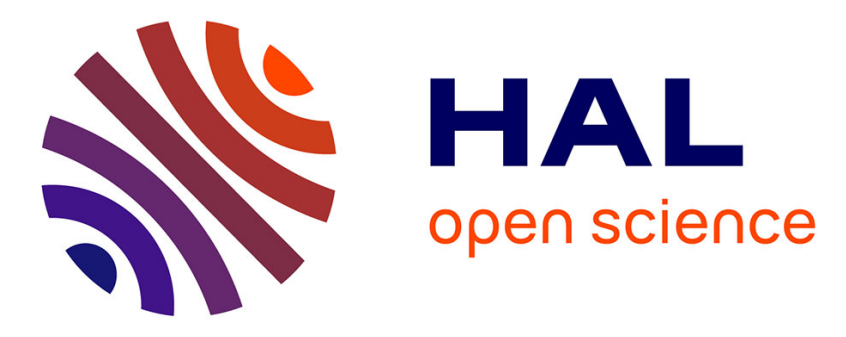

\title{
Tribo-aero-electrostatic separator for coarse granular insulating materials
}

Mohamed Miloudi, Lucian Dascalescu, Jia Li, Sofiane El-Mossouess, Karim Medles

\section{- To cite this version:}

Mohamed Miloudi, Lucian Dascalescu, Jia Li, Sofiane El-Mossouess, Karim Medles. Tribo-aeroelectrostatic separator for coarse granular insulating materials. IEEE Transactions on Dielectrics and Electrical Insulation, 2013, 20, pp.1510 - 1515. 10.1109/TDEI.2013.6633677 . hal-01104816

\section{HAL Id: hal-01104816 https://hal.science/hal-01104816}

Submitted on 19 Jan 2015

HAL is a multi-disciplinary open access archive for the deposit and dissemination of scientific research documents, whether they are published or not. The documents may come from teaching and research institutions in France or abroad, or from public or private research centers.

$$
\text { Copyright }
$$

L'archive ouverte pluridisciplinaire HAL, est destinée au dépôt et à la diffusion de documents scientifiques de niveau recherche, publiés ou non, émanant des établissements d'enseignement et de recherche français ou étrangers, des laboratoires publics ou privés. 


\title{
Tribo-aero-electrostatic Separator for Coarse Granular Insulating Materials
}

\author{
Mohamed Miloudi, Lucian Dascalescu, Jia Li, Sofiane El-Mossouess and Karim Medles \\ Institut PPRIME, UPR 3346, CNRS - University of Poitiers - ENSMA \\ IUT, 4 avenue de Varsovie, 16021 Angoulême Cedex, France
}

\begin{abstract}
The tribo-aero-electrostatic separator achieves the selective sorting of mixed granular insulating materials in a fluidized bed affected by an electric field orthogonally oriented to the direction of the fluidization air. The aim of the present paper is to optimize the design and the operation of such a separator, i.e. maximize the total mass of the granules collected at the two electrodes that generate the electric field. The experiments were performed for four different electrode configurations. The granular mixtures to be separated were composed of Acrylonitrile Butadiene Styrene (ABS) and High Impact Polystyrene (HIPS) originating from the recycling of waste electric and electronic equipment (WEEE). The typical granule size was in the range 2 to $4.5 \mathrm{~mm}$. The highest separation efficiency was obtained when the electric field in the active zone was intensified by the use of an additional electrode connected to the ground and when the collecting electrodes were covered by a thin insulating layer, preventing charge leakage from the particles in contact with them.
\end{abstract}

Index Terms - Triboelectricity, electrostatic processes, electrostatic separation.

\section{INTRODUCTION}

THE separation of mixed granular insulating materials is typically a two-step process: the materials are first charged by tribo-electric effect $[1,2]$, in vibratory, rotating or fluidizedbed devices [3-8], then introduced in an electric field to be sorted under the action of Coulomb forces: the positively and negatively charged granules are driven to opposite electrodes and collected in distinct compartments $[9,10]$. The problem is that certain granules carry enough charge to be electrostatically separated, while others exit the tribo-charging device with a less satisfactory charge level.

Better results could be obtained by increasing the duration of the tribo-charging process [11, 12], but this would diminish the hourly output of the installation and does not eliminate another major drawback: the acquired charge can significantly vary with the ambient humidity, and with the surface state of the processed granular materials [13]. The charging efficiency could be improved by thermal preconditioning of the materials and controlling the ambient atmosphere, but these operations would increase the cost of the processing [14].

In most of the existing installations [4, 14], the separation of charged particles is achieved in the electric field generated between two vertical electrodes. These installations have a rather poor throughput, and are not robust enough to the unpredictable variations of the ambient conditions and to the non-controlled changes of the physical and chemical features of the materials to be separated.

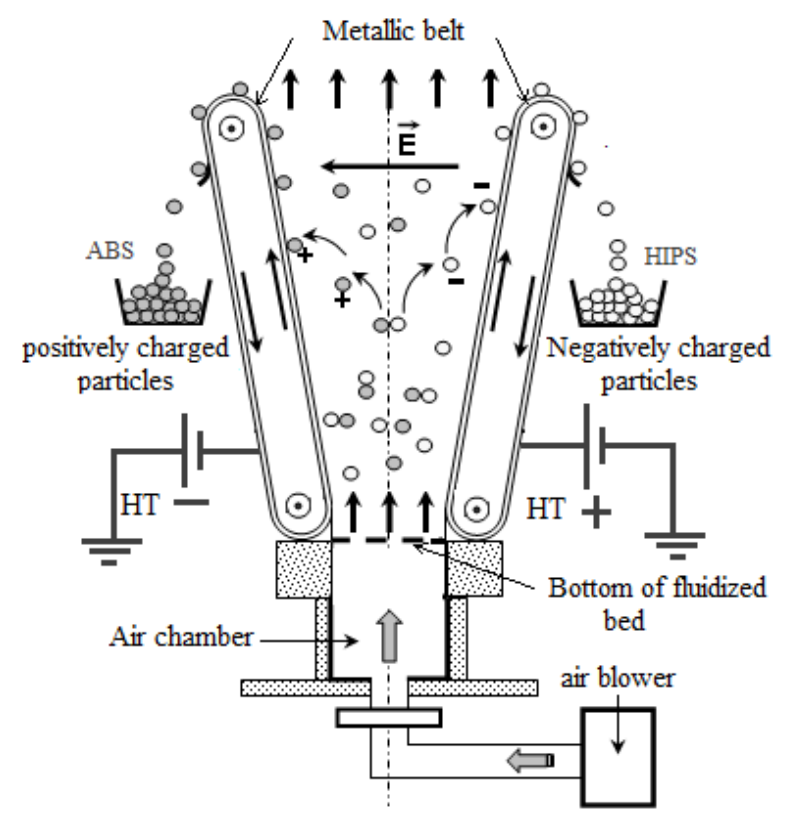

Figure 1. "Standard" configuration of the tribo-aero-electrostatic separator for mixed granular solids [16].

The installation described in a recent patent [16] is expected to avoid these drawbacks, by the simultaneous usage of the triboelectric effect, the Coulomb force and the electric image force (Figure 1), where the ABS and the HIPS gets respectively positive and negative charge. 


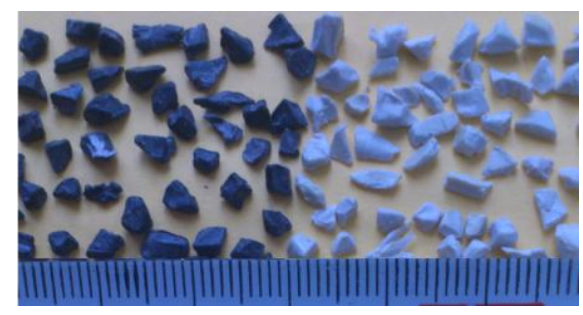

Figure 2. Aspect and size of ABS and HIPS granules (the ruler is in $\mathrm{mm}$ ).

Thus, the triboelectric effect provides the homogeneity of the electric charge acquired by the granules in a fluidized bed having the shape of a reverse truncated pyramid. The charged particles move in the electric field generated between two conveyor-belt-type high-voltage electrodes to the surface of which they are driven by the Coulomb force, ant to which they stay pinned by the electric image force.

The electrodes convey then the particles to the product collectors. The feed-rate of the separator is adjusted at a value which is equal to the sum of the mass of products collected in a time unit. As no uncharged particle can leave the separation chamber, the purity of the products recovered after separation is practically $100 \%$. On the other hand, each particle spends in the separator only the time necessary to acquire a charge highenough for it to be attracted by one of the electrodes. Thus, in case that the state of the surface of the materials and the ambient conditions are adequate, the particles are rapidly attracted to the electrodes and recovered in the product collector, so that the installation can be operated at high feed rates. Under unfavourable tribocharging conditions, the feed rate will be automatically reduced, so that to adjust itself to the longer residence time of the granules in the active zone of the separator.

The objective of this study is to improve the design of this tribo-aero-electrostatic separator, to allow the processing of a wide range of granular materials, in view of applications in the recycling industry [17-19]. The tests were performed for four different electrode configurations using a mixture of ABS and HIPS, which are commonly found in granular WEEE.

\section{EXPERIMENTAL PROCEDURE}

\subsection{MATERIAL}

The $2000 \mathrm{~g}$ samples were prepared as binary granular mixture of 50\% ABS and HIPS 50\%, originating from shredded out-of-use computer cases. The two sorts of granules were provided by APR2, Bonnières-sur-Seine, France, a WEEE recycler. The typical granule size was ranging between 2 and $4.5 \mathrm{~mm}$ (Fig. 2).

\subsection{ELECTRODE SYSTEM CONFIGURATIONS}

In order to improve the efficiency of the "standard" separator in the case of large particles ( 2 to $4.5 \mathrm{~mm}$ ), the bottom level of the fluidized bed was set at $20 \mathrm{~cm}$ below the bottom edge of the conveyors, so that to increase the residence time of the granules in the tribocharging device.

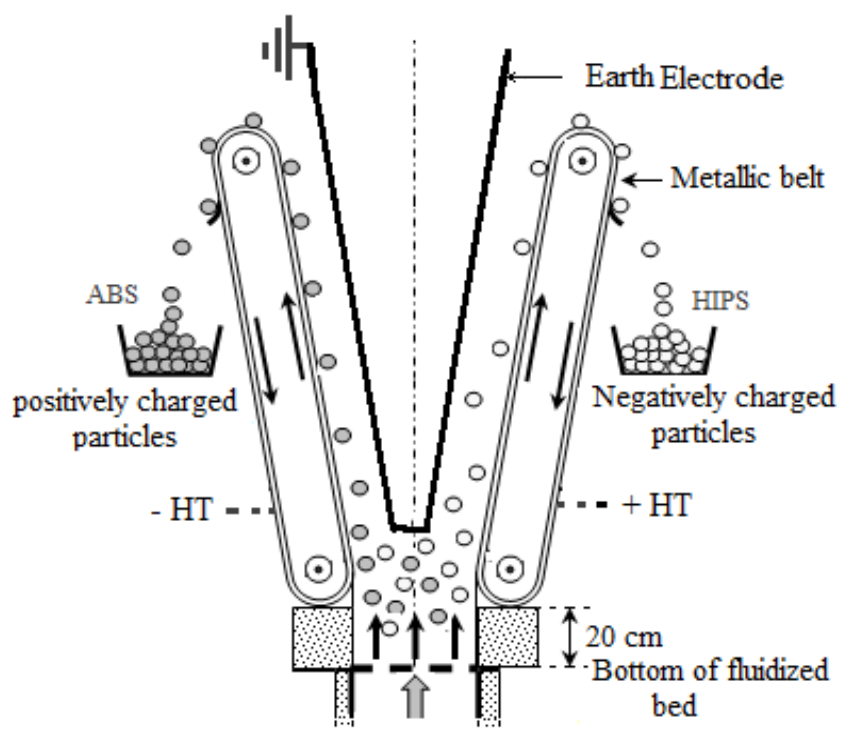

Figure 3. Electrode configuration II: bottom level of the fluidized bed $20 \mathrm{~cm}$ below the lower edge of the metallic belt conveyors and additionnal V-shaped earthed electrode.

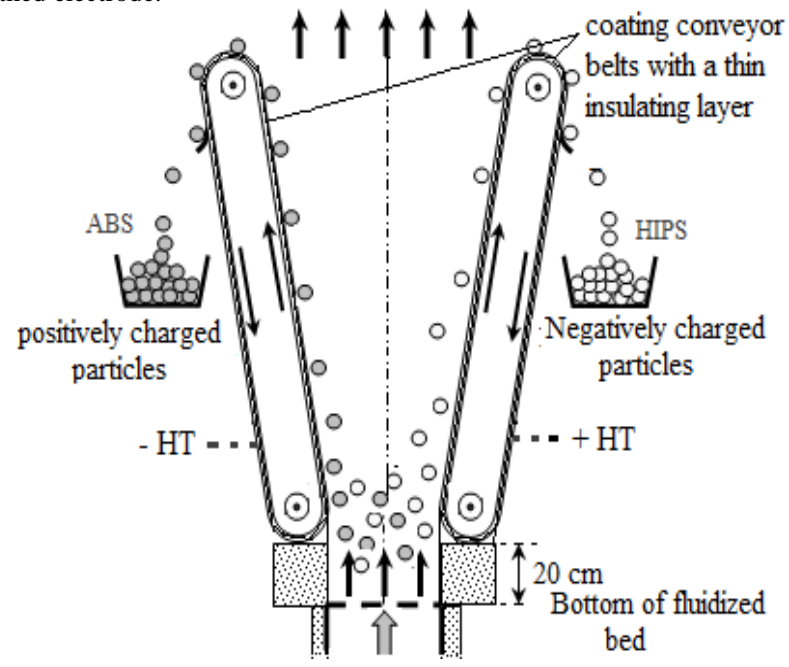

Figure 4. Electrode configuration III: bottom level of the fluidized bed $20 \mathrm{~cm}$ below the lower edge of the metallic belt conveyors and electrodes covered by a thin insulating layer.

Three new solutions have been tested:

(1) add a V-shaped earthed electrode to enhance the electric field (Figure 3);

(2) cover the electrodes with a thin insulating layer in order to prevent granule charge decay and increase the adhesion of the granules to the metallic belts (Figure 4);

(3) combine the two solutions (Figure 5).

\subsection{EXPERIMENTAL PROCEDURE}

All experiments included the following operations:

1. Charge the granular mixture for $t=4 \mathrm{~min}$, at full speed of the air blower motor (3600 RPM), and no high voltage applied to the electrodes; 


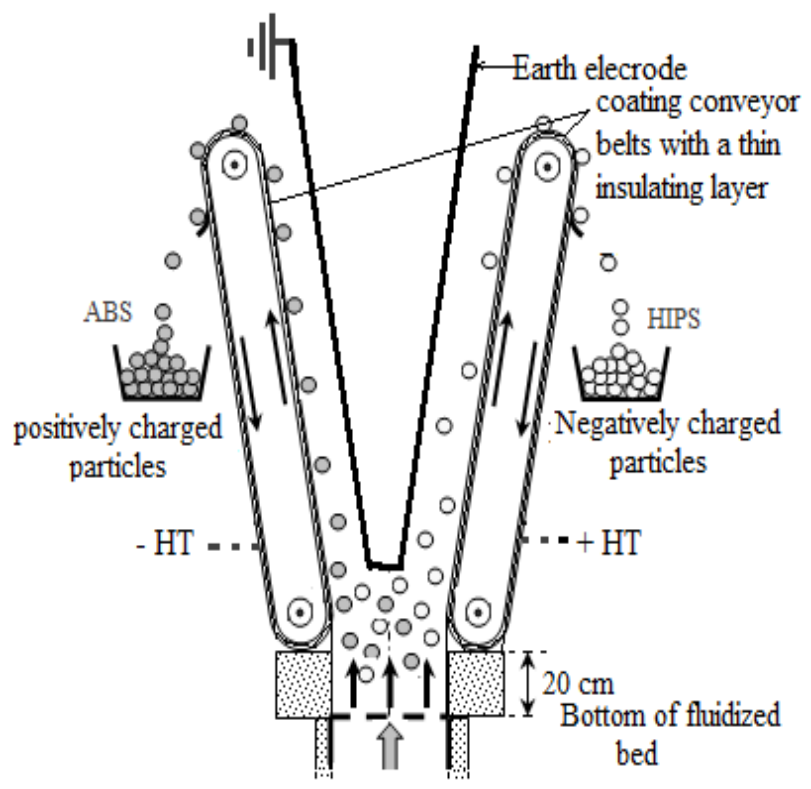

Figure 5. Electrode configuration IV: bottom level of the fluidized bed $20 \mathrm{~cm}$ below the lower edge of the metallic belt conveyors, additional Vshaped earthed electrode, and electrodes covered by a thin insulating layer.

2. Apply the high voltage $U= \pm 30 \mathrm{kV}$ to both electrodes, and start the metallic conveyor belts (speed: $16 \mathrm{~cm} / \mathrm{s}$ ) for simultaneous product recovery

3. Measure the quantities of products recovered after $t=4,10$ and $15 \mathrm{~min}$ (beyond $15 \mathrm{~min}$, there are no more particles collected at the electrodes).

The ambient conditions were stable: temperature $T=18 \pm 1^{\circ}$ $\mathrm{C}$ and relative humidity $R H=46 \pm 2 \%$.

\section{RESULTS AND DISCUSSION}

\subsection{PRELIMINARY EXPERIMENTS}

Two series of electrostatic separation experiments were performed in order to point out the specific difficulties related to the processing of coarse granules with Irregular shapes (size range: 2 to $4.5 \mathrm{~mm}$ ). The "standard" configuration in Fig. 1 was employed for the first series of tests, then a V-shaped earthed electrode similar to the one in Figure 3 was added, but without lowering the position of the air diffuser (i.e., the base level of the fluidized bed). The results obtained are summarized in Table 1 and plotted in Figure 6. Even the best recovery rates $(36.5 \%$ for the ABS and $15.8 \%$ for the HIPS) that were obtained after $t=15 \mathrm{~min}$, using the configuration with additional earthed electrode, are totally unsatisfactory.

The explanation of the poor efficiency of the separation is simple: charged granules accumulate fast at the bottom end of the two belt-type electrodes, but their charge is not sufficient to keep them "pinned" to the conveyors under the action of electric forces. These poorly-charged granules form a sort of a fence between the belts and the core of the fluidized bed, preventing the other granules to get to be collected at the electrodes.

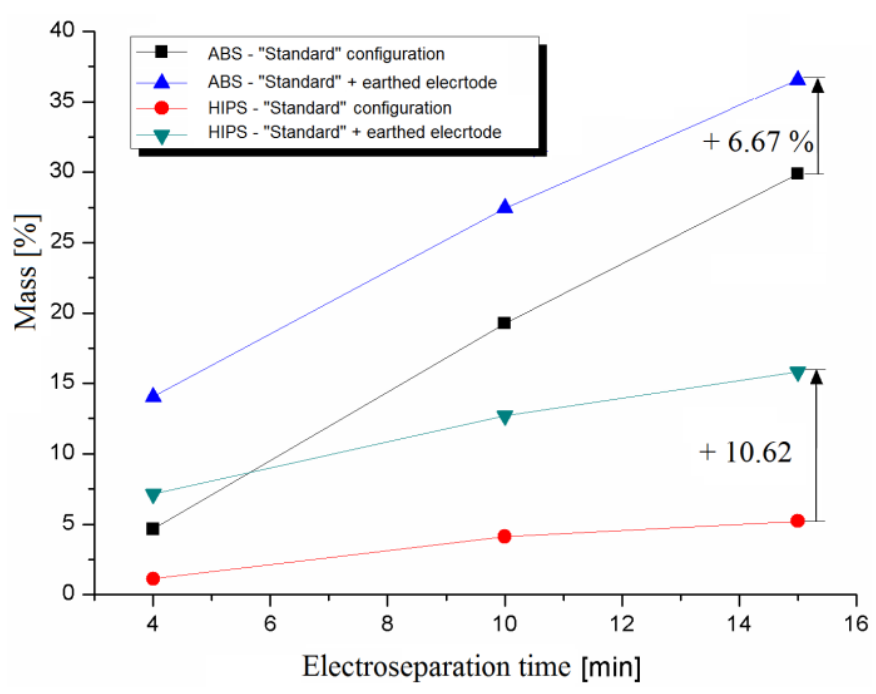

Figure 6. Mass recovery [\%] of ABS and HIPS, as function of the duration of the tribo-aero-electrostatic separation process, when using the "standard" configuration or adding a V-shaped earthed electrode.

Table 1. Mass recovery [\%] of ABS and HIPS after separation, when using the "standard" configuration or adding a V-shaped earthed electrode.

\begin{tabular}{ccccc}
\hline \hline \multirow{2}{*}{$\begin{array}{c}\text { Time } \\
t \\
{[\mathrm{~min}]}\end{array}$} & \multicolumn{3}{c}{ "Standard" } & \multicolumn{2}{c}{$\begin{array}{c}\text { "Standard" with additional } \\
\text { electrode }\end{array}$} \\
\cline { 2 - 5 } & ABS [\%] & HIPS [\%] & ABS [\%] & HIPS [\%] \\
\hline 4 & 4.6 & 1.1 & 14.1 & 7.1 \\
\hline 10 & 19.3 & 4.1 & 27.4 & 12.7 \\
\hline 15 & 29.9 & 5.2 & 36.5 & 15.8 \\
\hline \hline
\end{tabular}

This observation prompted the idea of lowering the base level of the fluidized bed by $20 \mathrm{~cm}$. In this way, the distance between the metal belt conveyors and the granules is larger, and the latter will need to acquire a higher level of charge before being attracted to the electrodes. The higher charges are expected to enhance their adhesion to the moving belts and facilitate their evacuation. All the experiments described hereafter were performed with the modified fluidized bed.

The differences in the mass recovery rates of ABS and HIPS can be explained by the position of the two materials in the triboelectric series. Thus, the ABS granules charge positively in contact with both the HIPS granules and the PMMA walls of the fluidized bed. The HIPS granules charge negatively in contact with ABS granules, but positively when colliding the PMMA walls. In absolute values, their charge will be at a lower level than that of the ABS granules. As a consequence, fewer of them will be separated from the granular mixture.

\subsection{COMPARISON BETWEEN FOUR ELECTRODE CONFIGURATIONS}

The percentage of the initial mass of ABS and HIPS granules recovered in the collector after the tribo-electro-static separation has been calculated as the average of at least three experiments performed for each of the four electrode configurations under study (see Figures 1, 3, 4 and 5). 


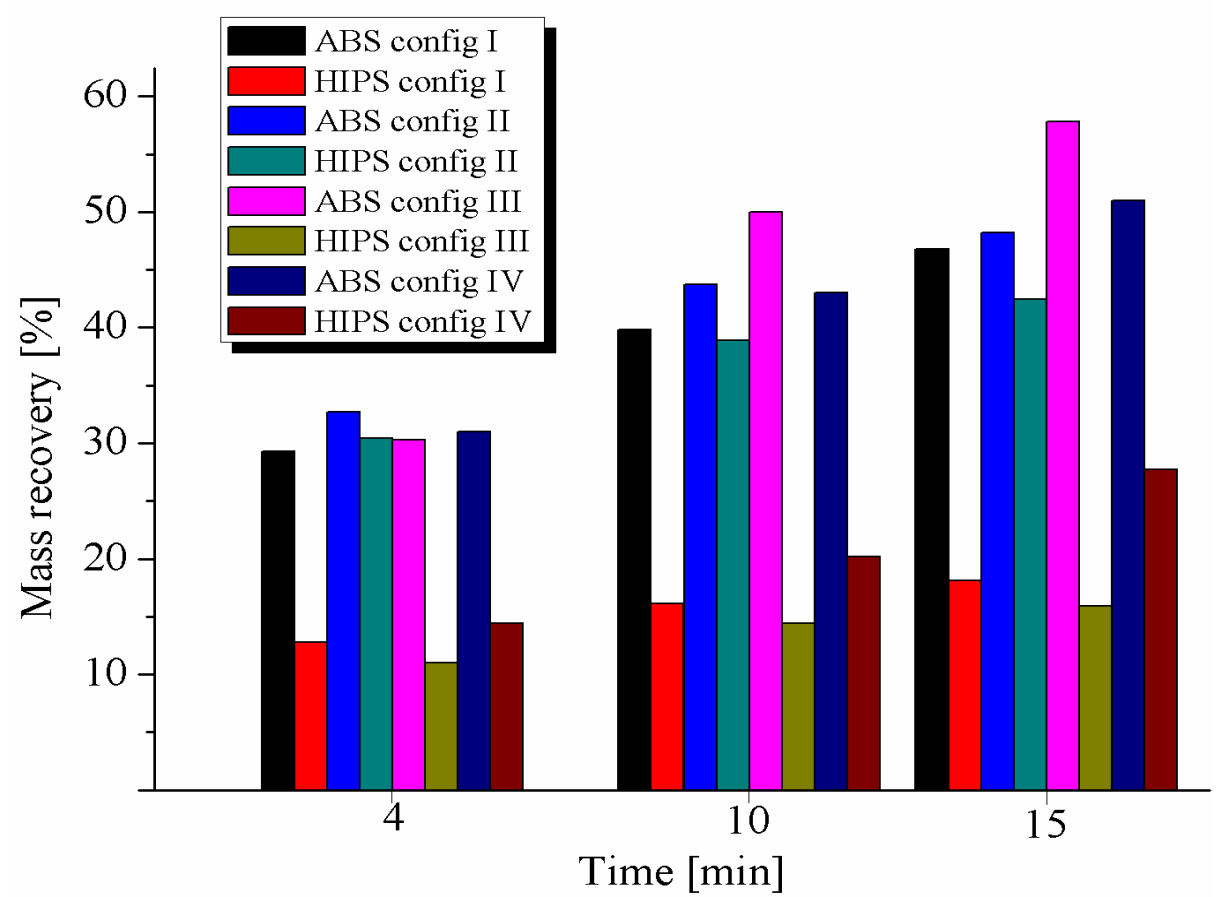

Figure 7. Mass recovery [\%] of ABS and HIPS for the four configurations of the electrode system after 4, 10 and 15 minutes.

Table 2. Comparison between the mass recovery [\%] of ABS and HIPS for the four configurations of the electrode system.

\begin{tabular}{ccccccccc}
\hline \hline \multirow{2}{*}{$\begin{array}{c}\text { Time } t \\
\text { [min] }\end{array}$} & \multicolumn{9}{c}{ Electrode configuration } \\
& I: "standard", modified* & \multicolumn{2}{c}{$\begin{array}{l}\text { II: with additional } \\
\text { earthed electrode }\end{array}$} & $\begin{array}{c}\text { III: electrodes covered } \\
\text { with an insulating layer }\end{array}$ & $\begin{array}{c}\text { IV: combination of } \\
\text { II and III }\end{array}$ \\
\cline { 2 - 8 } & ABS [\%] & HIPS [\%] & ABS [\%] & HIPS [\%] & ABS [\%] & HIPS [\%] & ABS [\%] & HIPS [\%] \\
\hline 4 & 29.3 & 12.8 & 32.7 & 30.4 & 30.3 & 11.0 & 31.0 & 14.4 \\
\hline 10 & 39.8 & 16.1 & 43.7 & 38.9 & 50.0 & 14.4 & 43.0 & 20.2 \\
\hline 15 & 46.8 & 18.1 & 48.2 & 42.4 & 57.8 & 15.9 & 51.0 & 27.7 \\
\hline \hline
\end{tabular}

* the base of the fluidized bed at $20 \mathrm{~cm}$ below the bottom edge of the metal-belt electrodes

The results given in Table 2 and plotted in Fig. 7 for the "standard" modified configuration confirm the prediction formulated after the preliminary experiments. Thus, by lowering the position of the air diffuser (i.e., the base of the fluidized bed), the recovery of ABS granules increased to $29.3 \%$, from $4.6 \%$ with the "standard" position, at $t=4 \mathrm{~min}$; it doubled, from $19.3 \%$ to $39.8 \%$, at $t=10 \mathrm{~min}$, and progressed by $50 \%$, from $29.9 \%$ to $46.8 \%$, at $t=15 \mathrm{~min}$. The recovery of HIPS granules remained very poor, as compared to ABS, because of the detrimental effect of the granule-to-wall impacts. This tribocharging mechanism seems to favour the ABS charging.

The additional earthed electrode (configuration II) is beneficial to collection of both ABS and HIPS granules. The quantities of products collected in this configuration are higher than in any of the other three cases under study (Table 3). This can be easily explained by examining the mathematical formulation of the condition for the separation of a spherical granule of radius $r$, mass $m$, and charge $Q$ :

$$
\mu\left(F_{e}+F_{i}+G \sin \alpha\right) \geq G \cos \alpha
$$

where $\mu$ is the friction coefficient, $G=m g$ is the gravitational force, $\alpha$ is the angle at which the belt is inclined with respect to the vertical, $F_{e}=Q E$ is the Coulomb force, with $E$ being the local strength of the electric field at the surface of the electrode, and $F_{i}=$ $Q^{2} /\left[4 \pi \varepsilon_{0}(2 r)^{2}\right]$ is the electric image force, with $\varepsilon_{0}$ being the electric permittivity of air. The intensification of the electric field enhances the Coulomb force that pins the charged granule to the surface of the electrode.

Table 3. Variation of mass recovery [\%] of ABS and HIPS granules in the configurations II to IV, as compared to the configuration I.

\begin{tabular}{ccccccc}
\hline \hline \multirow{2}{*}{$\begin{array}{c}t \\
{[\min ]}\end{array}$} & \multicolumn{4}{c}{ Compared electrode configurations } \\
\cline { 2 - 7 } & \multicolumn{2}{c}{ II - I } & \multicolumn{2}{c}{ III - I } & \multicolumn{2}{c}{ IV - I } \\
\cline { 2 - 7 } & ABS & HIPS & ABS & HIPS & ABS & HIPS \\
\hline 4 & 3.4 & 17.6 & 1.0 & -1.8 & 1.7 & 1.6 \\
\hline 10 & 3.9 & 22.8 & 10.2 & -1.7 & 3.2 & 4.1 \\
\hline 15 & 1.4 & 24.3 & 11.0 & -2.2 & 4.2 & 9.6 \\
\hline \hline
\end{tabular}


This effect is more spectacular in the case of poorly charged HIPS granules: the stronger electric field forces more than double the quantities of the recovered material, which increase from $16.1 \%$ to $38.9 \%$, after $t=$ $10 \mathrm{~min}$. According to equation (1), the lower the value of $Q$, the higher is the field $E$ for which a granule can be pinned to an electrode and separated from the granular mixture. The ABS granules, which charge better that the HIPS ones, separate quite well even at low values of $E$. In their case, the increase of $E$ is accompanied by only a moderate increase of mass recovery.

The presence of the insulating coating (configuration III) had opposite effects on the two kinds of granules. This can be explained by the observations made in a previous study, which pointed out that the ABS granules are more affected by the ambient humidity: as they are more hydrophilic than the HIPS, a thin water film can form at their surface, which favours the partial leakage of charge $Q$ to the metallic belt. The insulating layer drastically limits this leakage. As a consequence, the ABS granules better preserve their charge $Q$ and stay longer in contact with the belt collectors than in the absence of the layer of thickness $a$, in spite of the reduction of the electric image force

$$
F_{i}=Q^{2} /\left\{4 \pi \varepsilon_{0}[2(r+a)]^{2}\right\} \leq Q^{2} /\left[4 \pi \varepsilon_{0}(2 r)^{2}\right] .
$$

The increased friction coefficient $\mu$ between the granules and the rough surface of the insulating layer also favours ABS recovery.

In the case of HIPS granules, which are intrinsically characterized by very slow charge decay when in contact with an electrode, the presence of the insulating layer has less effect on the amount of the residual charge $Q$. The main effect of this layer is the reduction of the electric image force $F_{i}$. Therefore, they detach easier from the belt, and the recovery is poorer than in the "standard" configuration. Surprisingly, the configuration IV, which combined the effects of the configurations II and III, provided the best results for neither the HIPS nor the ABS granules. In the case of the HIPS granules, the increase of the Coulomb $F_{e}$ force due to the intensification of the electric field $E$ generated by the additional electrode was not enough to compensate for the reduction of the electric image force $F_{i}$, due to the presence of the insulating layer at the surface of the belt electrode.

As for the fact that the recovery of ABS granules was poorer in configuration IV than in configuration III, this can be explained by the wear of the PMMA walls, which play an important part in the charging of ABS granules. Indeed, this set of the experiments was performed after the completion of all the others, and the state of the inner walls of the fluidised bed was altered as compared to the previous tests, and the level of the charge $Q$ was lower. This correlation between the wear of the material and its capacity to exchange charge by triboelectric effect had been pointed out in [6].

\section{CONCLUSIONS}

The tests carried out on an industrial pilot installation are very encouraging. The efficiency of the tribo-aero- electrostatic separation of coarse granular plastics can be improved using one or more or the following solutions:

(1) lowering the position of the air diffuser with respect to the bottom edge of the belt-type electrodes; further experiments are needed to optimize the location of the base level of the fluidised bed.

(2) covering the metal-belt conveyors with a thin insulating layer, to modify the friction coefficient and prevent the granule-to-electrode charge leakage; the nature and the thickness of the layer should make the object of further studies.

(3) making use of an additional V-shaped earthed electrode to intensify the electric field at the surface of the two electrodes, and hence intensify the electric forces that act on the charged granule.

Research is in progress to clarify the role of granuleto-wall collisions in the tribo-charging of plastics in fluidised bed devices, and optimize the electrode configuration using experimental design methodology.

\section{ACKNOWLEDGMENTS}

The Algerian Government provided to the first author (M.M.) 18 months Ph.D. scholarship at the University of Poitiers. Another author (J.L) benefited from 12 months post-doc fellowship from the Chinese Government. Fruitful discussions with Eng. M. Bicer, from APR2, Bonnières-sur-Seine, on the electrode configurations of the separator are acknowledged with thanks. Prof. A. Iuga, Prof. A. Samuila, Dr. Eng. L. Calin, Dr.-Eng. C. Dragan, Eng. V. Dragan, Drd. Eng. M. Bilici have contributed to the successful start of this project.

\section{REFERENCES}

[1] G.S.P. Castle, "Contact charging between insulators," J. Electrostat., Vols. 40 and 41, pp. 13-18, 1997.

[2] L. Calin, L. Caliap, V. Neamtu, R. Morar, A. Iuga, A. Samuila, and L. Dascalescu, "Tribocharging of granular plastic mixtures in view of electrostatic separation,” IEEE Trans. Ind. Appl., Vol. 44, pp. 1045-1051, 2008.

[3] M. Blajan, R. Beleca, A. Iuga, and L. Dascalescu, "Triboelectrification of granular plastic wastes in vibrated zigzag shaped square pipes in view of electrostatic separation," IEEE Trans. Ind. Appl., Vol. 46, pp. 1558-1563, 2010.

[4] I.I. Inculet, G.S.P. Castle, and J.D. Brown, "Electrostatic separation of plastics for recycling," Part. Sci .Technol, Vol. 16, pp. 91-100, 1998.

[5] M. Miloudi, K. Medles, A. Tilmatine, M. Brahami, and L. Dascalescu, "Modeling and optimization of a propeller-type tribocharger for granular materials," J. Electrostat., Vol. 69, pp. 631-637, 2011.

[6] L. Dascalescu, A. Urs, S. Bente, M. Huzau, and A. Samuila, "Charging of mm-size insulating particles in vibratory devices," J. Electrostat., Vol. 63, pp. 705-710, 2005. 
[7] A. Iuga, L. Calin, V. Neamtu, A. Mihalcioiu, and L. Dascalescu, "Tribocharging of plastics granulates in a fluidized bed device," J. Electrostat., Vol. 63, pp. 937-942, 2005.

[8] L. Calin, A. Mihalcioiu, A. Iuga, and L. Dascalescu, "Fluidized bed device for plastic granules triboelectrification," Part. Sci. Technol., Vol. 25, pp. 205-211, 2007.

[9] K. Haga, "Applications of the electrostatic separation technique," in J.S. Chang, A.J. Kelly, and J.M. Crowley (Eds), Handbook of Electrostatic Processes, NewYork, NY, Marcel Dekker, 1995.

[10] Y. Higashiyama and K. Asano, "Recent progress in electrostatic separation technology," Part. Sci. Technol, Vol. 16, pp. 77-90, 1998.

[11] M. Bilici, L. Dascalescu, C. Dragan, O. Fati, A. Iuga, and A. Samuila, "Tribocharging and electrostatic separation of of mixed granular solids in fluidized bed devices," IEEE Trans. Dielectr. Electr. Insul., Vol. 18, pp. 1476-1483, 2011.

[12] C. Dragan, O. Fati, M. Radu, L. Calin, A. Samuila, and L. Dascalescu, "Tribocharging of mixed granular plastics in a fluidized bed device," IEEE Trans. Ind. Appl., Vol. 47, p. 1922 $-1928,2011$.

[13] M. Miloudi, M. Remadnia, C. Dragan, K. Medles, A. Tilmatine, and L. Dascalescu, "Experimental study of study of the optimum operating conditions of a pilote-scale tribo-aero-electrostatic separator of mixed granular solids," IEEE Trans. Ind. Appl., Vol. 49, No. 2, pp. 699-706, 2013.

[14] J. Li and L. Dascalescu, "New technical solutions for improving the tribo-electrostatic separation of mixed granular solids," Recent Patents on Engineering, Vol. 6, pp. 104-115, 2012.

[15] S. Bendimerad, A. Tilmatine, M. Ziane, and L Dascalescu, "Plastic wastes recovery using freefall triboelectric separator," Int. J. Environ. Studies, Vol. 66, pp. 529-538, 2009.

[16] L. Calin, and L. Dascalescu, "Method for Electrostatically Separating a Granule Mixture Made of Different Materials, and Device for Implementing Same," Patent FR2943561 (2009), WO2010109096 (2010)

[17] H. Aizawa, H. Yoshida, and S. Sakai, "Current results and future perspectives for Japanese recycling of home electrical appliances," Res. Cons. Recycl, Vol. 52, pp. 1399-1410, 2008.

[18] S.M. Al-Salem, P. Lettieri, J. Baeyens, "Recycling and recovery routes of plastic solid waste (PSW): A review," Waste Management, Vol. 29, pp. 2625-2643, 2009.

[19] F.O. Ongondo, I.D. Williams, and T. J. Cherrett, "How are WEEE doing? A global review of the management of electrical and electronic wastes," Waste Management, Vol. 31, pp. 714$730,2011$.

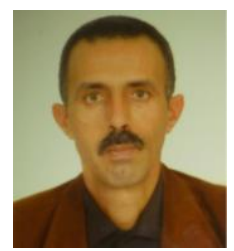

Mohamed Miloudi (M'12) was born in Sidi Bel Abbes, Algeria, in 1967. He received the Dipl.-Eng. and the Magister (Dr.-Eng.) degrees in electrical engineering from the University Djillali Liabes, Sidi Bel Abbes, Algeria, in 1991 and 2006 respectively. He spent fifteen years in the electronics industry and industrial production; from 2006 he is an Assistant Professor at the University Djillali Liabes, Sidi Bel Abbes, Algeria He obtained his PhD degree in 2012, with a thesis he partly prepared under the supervision of Prof. Lucian Dascalescu at the University Institute of Technology, Angoulême, France, He has published several scientific papers in international and national journals, as well as in conference proceedings. His research interests include high-voltage engineering, triboelectricity, and electrostatic separation technologies.

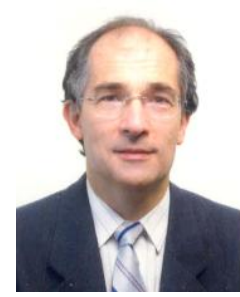

Lucian Dascalescu (M'93, SM'95, F'09) obtained the Dipl.-Eng. degree with first class honors from the Faculty of Electrical Engineering, Technical University of ClujNapoca, Romania, in 1978, and received the Dr. Eng. degree in electrotechnical materials, from the Polytechnic Institute of Bucharest, Romania. in 1991. He obtained the Dr. Sci. degree in 1994 from the University "Joseph Fourier", Grenoble, France.
His professional carrier began at CUG (Heavy Equipment Works), Cluj-Napoca, Romania. In 1983, he moved to the Technical University of Cluj-Napoca, as Assistant Professor, later becoming an Associate Professor of Electrical Engineering. From October 1991 to June 1992, he received a Research Fellowship at the Laboratory of Electrostatics and Dielectric Materials (LEMD), Grenoble, France, where he returned in January 1994, after one year as an Invited Research Associate and Lecturer at Toyohashi University of Technology, Japan. For four years, he taught a course in electromechanical conversion of energy at the University Institute of Technology, Grenoble, France. In September 1997, he was appointed Professor of Electrical Engineering and Automated Systems and Head of the Electronics and Electrostatics Research Unit at the University Institute of Technology, Angoulême, France. Since 1999, he has also been Head of the Department of Management and Engineering of Manufacturing Systems. At present he is Distinguished Professor and Head of the Electrostatics of Dispersed Media Research Unit, which is part of the EHD Group, PPRIME Institute, at the University of Poitiers. L. Dascalescu is the author of several textbooks in the field of electrical engineering and ionized gases. He holds 16 patents, has written more than 160 papers, and was invited to lecture on the electrostatics of granular materials at various universities and international conferences all over the world.

Prof. Dascalescu is Fellow IEEE/IAS, Vice-Chair of IEEE France Section, Past-Chair and Technical Program Chair of the Electrostatic Processes Committee. He is a member of Electrostatics Society of America, Electrostatics Society of Romania, Société Française d'Electrostatique, and Club Electrotechnique, Electronique, Automatique (EEA) France.

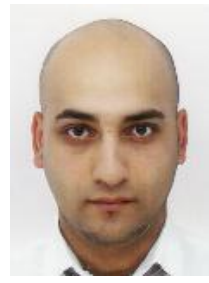

Sofiane El Mossouess obtained the B.Sci. in Electrical Engineering from the University Djillali Liabes, Sidi-Bel-Abbes, Algeria, in 2008. the M. Sci. in Electrical Engineering from the University of Poitiers, France, in 2011, and has recently completed a MBA at the Institute of Economics and Administration in Poitiers. France. His present interests include instrumentation and high-voltage engineering.

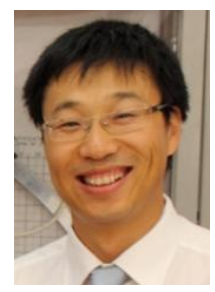

Jia $\mathrm{Li}$ obtained the B.Sci. and $\mathrm{PhD}$ degrees in Materials Science and Engineering, both from Shanghai Jiao Tong University, in 2003 and 2008, respectively. At present he is Associate professor with the School of Environmental Science and Engineering, at the same university. In 2011/2012 he benefited of a Visiting Scientist scholarship, offered by the Chinese Gouvernment, for working with Prof. Lucian Dascalescu at the University Institute of Technology Angoulême, France. Dr. Li coauthored more than 20 papers, holds 3 patents and was in charge of several projects in the field of waste recycling.

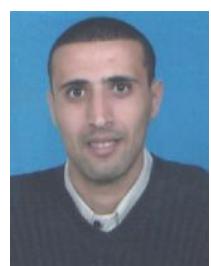

Karim Medles (M'09) was born in Tipaza, Algeria, in 1972. He received the Dipl.-Eng and the Magister (Dr.-Eng.) degrees in electrical engineering from the University Djillali Liabes, Sidi Bel Abbes, Algeria, in 1994 and 1999, respectively. He joined the faculty of that university in 1999, as a Senior Lecturer with the department of electrical engineering, where he currently is Full Professor. He obtained his $\mathrm{PhD}$ degree in 2006 from the University Djillali Liabes, Sidi Bel Abbes, Algeria, with a thesis he partly prepared under the supervision of Prof. Lucian Dascalescu at the University Institute of Technology, Angoulême, France, with a 18month research scholarship awarded by the Algerian Government. He is the head of Electrostatics and Methodology Research Unit of IRECOM Laboratory, University Djillai Liabes, Sidi-Bel-Abbes, Algeria. He has published several scientific papers in international and national journals, as well as in conference proceedings. He was invited several times as a visiting scientist in France. His current research interest includes high-voltage engineering and electrostatics. 